\title{
Online Laboratory in Digital Electronics Using NI ELVIS II+
}

\author{
http://dx.doi.org/10.3991/ijim.v9i2.4385 \\ Ahmed Naddami ${ }^{1}$, Ahmed Fahli ${ }^{1}$, Mourad Gourmaj ${ }^{1}$, Mohammed Moussetad ${ }^{2}$ \\ ${ }^{1}$ Université Hassan 1, Settat, Maroc \\ ${ }^{2}$ Université Hassan 2 Mohammedia, Casablanca, Maroc
}

\begin{abstract}
This work is part of the e-Sience project, which is realized in the framework of the Tempus project coordinated by Bordeau University and financed by the European Union. The "e-Sience" project aims to create a network of online labs in the Maghrebian countries.
\end{abstract}

The present paper presents our recent work to extend our online laboratory, the Khouribga OnlineLab at Hassan the 1st university in Morocco. It will focus on the development of a digital online laboratory supporting experiments in the fields of combinational logic circuits, sequential electronics, and digital multiplexer. The developed system combines NI ELVIS II+ and the NI digital Electronics FPGA board.

By using the interactive version of iLab Shared Architecture, students will have complete access to manage and control the system in real time.

Index Terms-e-Sience; iLab; OnlineLab; Measurement; real time; online labs; FPGA; ELVIS.

\section{INTRODUCTION}

Due to growth in the number of students at Hassan the $1^{\text {st }}$ university and the expensive nature of experiments, the existing hands-on laboratories are not enough. Furthermore, since modern instruments are not being acquired, practical work is limited to conventional laboratories, so a large number of students cannot get the experiences they need. [1]

However, implementing online labs should help faculty overcome the lack of experiments by giving students access to the online labs at any time and from anywhere. For this reason, we are engaged in the "e-Sience" project to implement online labs with other partners, especially from France, Austria, Romania, Greece, Tunisia and Algeria.

In this paper, we present the implementation of an online laboratory in digital electronics, which is part of the second year courses in our engineering programs. This laboratory represents an ideal and integral component in engineering education. It helps students understand theoretical concepts, develop their social skills, and maintain their professional to prepare them for professional life. Our online lab will give students the chance to access courses and remote practical work via the internet.

Remote sessions are based on the development of internet technologies and science information technology that help both students and teachers access real experiments on real hardware through the internet. It presents high quality features and is easy to use. Recently, remote laboratories have widely been adopted by several institutes, especially in electrical and electronic engineering as well as digital and sequential electronics. These disciplines are the target of this work [3].

It is almost impossible to find a part of society that has not been touched by digital electronics [4]. They have become the most significant development in the history of society [5]. Digital electronics is found in all areas of air/sea/land defense, like semiconductor components, ASIC design, FPGA and CPLD programming, IP address blocking design, design of electronic cards.

The present work focuses on the development and implementation of an online digital laboratory to enhance education in the electrical and electronic engineering fields based on the "heart" of remote laboratories: NI ELVIS II+' Educational Laboratory Virtual Instrumentation Suite' [6].

\section{KHOURIBGA ONLINELAB}

The Khouribga OnlineLab in Hassan $1^{\text {st }}$ university in Morocco is one of several laboratories developed in Tunisia and Algeria within the e-Sience project (Fig.1). eSience was inaugurated on the $28^{\text {th }}$ of June 2013 in Khouribga and is considered to be the first laboratory developed in the e-Sience project group based on the Interactive Shared Architecture (ISA) available via http://www.onlinelab-uhp.ma/.

e-Sience is seeking to create a network of remote labs in the countries already mentioned to modernize the educational processes in science and technology [7 and 10]. It consists of

- Implementing a network of online labs in Maghrebian countries.

- Modernizing the educational processes in Maghrebian countries.

- Adapting content to the developments in science and technology.

- Taking into account the expectations of the professional world.

- Implementing practical courses for distance education.

- Creating teaching units in an e-Learning format

- Setting up and using a Learning Management System (LMS).

- Evaluating the newly created educational resources

- Using the pedagogical resources.

Since its inception, the Khouribga, OnlineLab (Fig.2) has been cooperating with other remote laboratories. Recently, it has been cooperating with WebLab-Deusto, Bilbao, which is an open source RLMS (Remote Laborato- 
ry Management System) developed by the University of Deusto in Spain in October 2004[8]. The cooperation started through experiments with the VISIR (Virtual Instrument in the Reality) electronic platform of WebLabDeusto from our own Laboratory by using the federation of remote laboratories (Fig.3), which is aiming to enable two or more different systems. These systems, located in different entities (universities, secondary schools, research centers), can share laboratories [9].

\section{RELATED WORK}

\section{A. Architecture System}

\section{1) Hardware Implementation}

The hardware part of this online digital laboratory contains mainly the NI ELVIS II+ and the NI Digital Electronics FPGA Board.

\section{a) NI ELVIS II+}

NI ELVIS is low cost and is the most used hardware platform for developing remote laboratories in several fields: concepts in circuits, microcontrollers, controls, telecommunication, measurements and digital electronics [6]. NI ELVIS is a hands-on design and prototyping platform that integrates the 12 most commonly used instruments, including oscilloscope, digital multimeter, function generator, and bode analyzer. This work is based on the implementation of digital electronics. So, NI ELVIS has been specifically defined to use Boolean logic, digital electronics, and FPGA concepts at college and university laboratories [11].

NI ELVIS uses a USB cable to connect the workstation to the computer. It can also be programmatically accessed and controlled within NI LabVIEW, a visual programming language based on a graphical block diagram user interface.

\section{b) NI Digital Electronics FPGA Board}

The new NI Digital Electronics FPGA "Fieldprogrammable gate array Board" is ideal for teaching digital electronics and digital design concepts. It is a circuit development platform based on the XC3S500E Xilinx Spartan-3E FPGA that was designed to help educators teach digital electronics with access to real world signals and instrumentation. It also includes the necessary I/O to teach and use the basics of advanced digital electronics. The most important characteristics of the NI Digital Electronics FPGA Board are fully integrated and very useful with the NI ELVIS platform. This integration gives the ability to build comprehensive test bed benches and mixed-signal circuits that can be designed and tested in one platform (Fig.4) [12].

\section{2) Software Implementation}

To make the digital online laboratory remotely accessible via internet, we are using the interactive version of ISA [13], based on a web service that provides a management system for sharing laboratories among different universities. It offers a complete tool to users, such as user account management, scheduling and data storage.

The ISA is a robust, scalable, open-source infrastructure that provides a framework for the development and deployment of remote laboratories. ISA is divided into different kinds of laboratories: Batched laboratories and Interactive Laboratories [14]-[15]. In our laboratory, we are using the second category, which supports real time

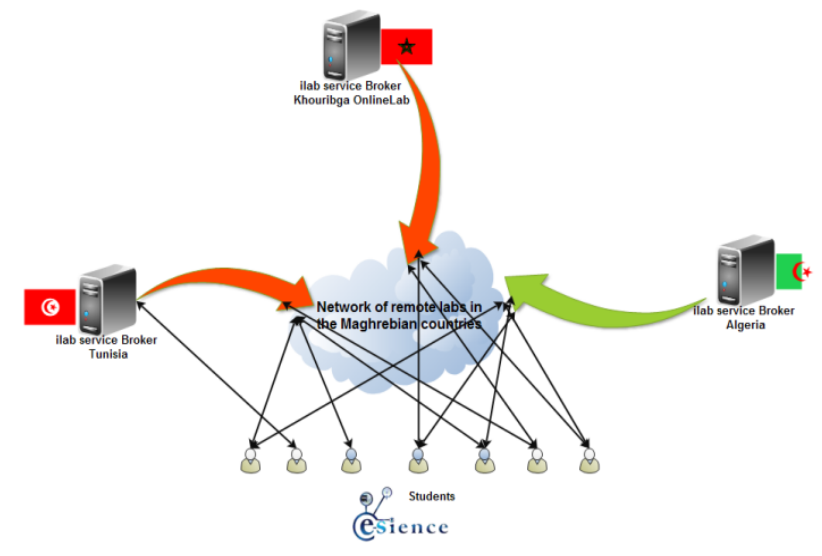

Figure 1. Network of online labs in maghrebian countries

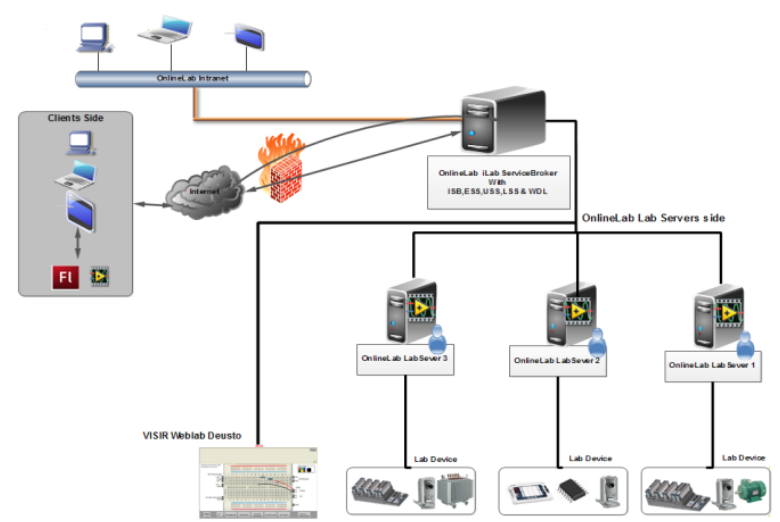

Figure 2. Khouribga OnlineLab Architecture

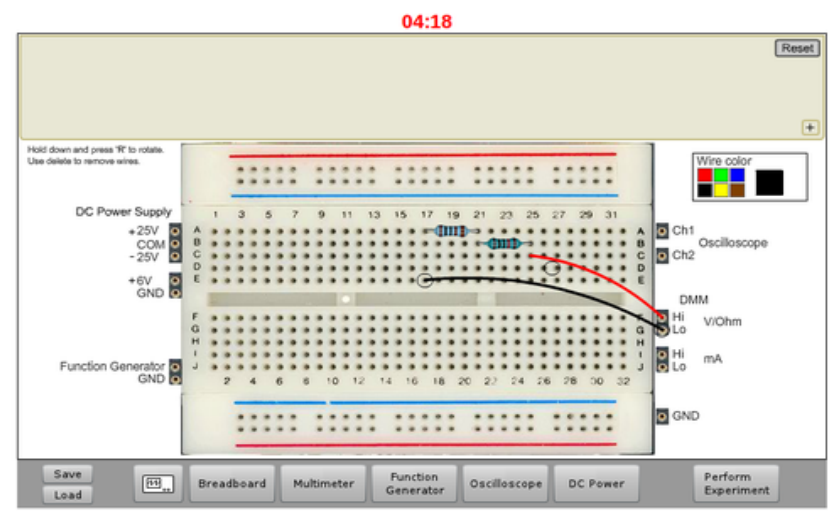

Figure 3. VISIR breadboard

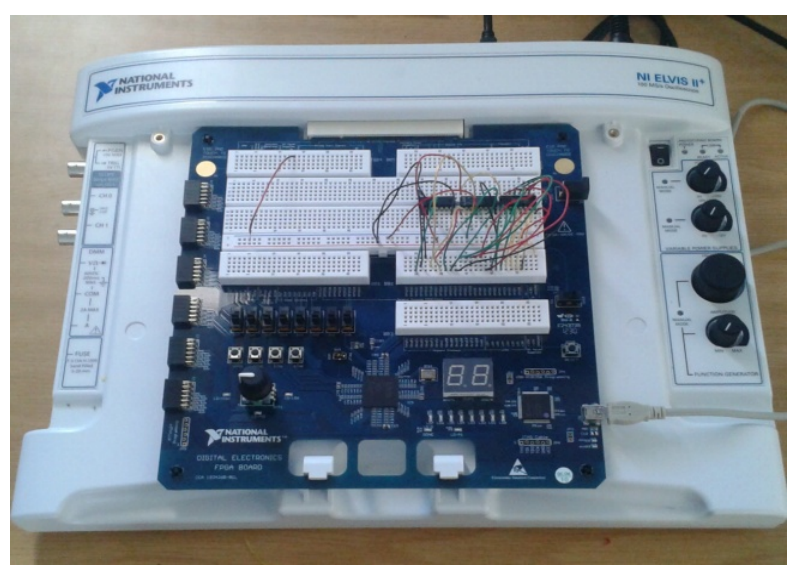

Figure 4. NI Digital Electronics FPGA Plugged into NI ELVIS II 
experiments. This category is also divided into three-tiered architecture consisting of: a lab client, a Service Broker and a lab server.

The Lab Client is a user interface. In this case, it is the front panel of the LabVIEW Virtual Instrument that allows users to configure and run an experiment. The Service Broker is a web service and the core of the ISA, which provides functionality and management tools, authorizes access to experiments and data storage, and facilitates communication between the Lab Server and the Lab Client as a middleware. The Lab Server is the machine connected to the NI ELVIS. It is responsible for receiving experiment submissions, translating them into instrument and specific commands, executing those commands, and passing the results back through the Service Broker to the user. In addition to this, the interactive ISA introduces three services: the Experiment Storage Service (ESS), which allows the Service Broker, Lab server and Lab Client to store experiment data. The Lab-Side Scheduling Service (LSS), in conjunction with User Side Scheduling Service (USS), helps its users manage reservation of experiments in advance (Fig.5).

\section{3) LabVIEW graphical programming}

The great variety of LabVIEW's graphical system design environment's Boolean and numeric controls/indicators, together with the wealth of programming structures and functions, make LabVIEW an excellent tool to visualize and demonstrate many of the fundamental concepts of digital electronics [16]. Also, we can create interactive front panels in LabVIEW that interface with the FPGA, change the parameters, and show the results of the designs reflected immediately on the front panel (Fig.6).

\section{EXPERIMENT SETUP}

The online digital laboratory supports several experiments based on the FPGA. These experiments are the digital logic gates, sequential logic, seven segment display and full Adder. These experiments are remotely controlled by using the interactive version of ISA via the internet.

\section{A. Running a remote Experiment}

As we have already described, our experiment is deployed in the Interactive Shared Architecture; however, the student launches and performs the Service Broker available via http://www.onlinelab-uhp.ma/. If the user is authorized to use the experiment, he /she selects the digital logic experiment and then chooses the available time to launch it (Fig.7).

\section{B. Digital Logic Gates Remote Experiment}

Gates are elementary building blocks of digital logic circuits as well as building blocks of more complex logic circuits. These devices function by "opening" or "closing" to admit or reject the passage of a logical signal; every terminal is in one of the two binary conditions: low (0) or high (1).

The aim of this experiment is to study the basic logic gates (AND, XOR and OR) by verifying the performance of those gates using a Truth table. Students participating in this experiment observe the pulse response of the logic gates.

The basic AND gate consists of two inputs and an output. If the two inputs are A and B, the output (often called $\mathrm{Q})$ is "on" only if both A and B are also "on."

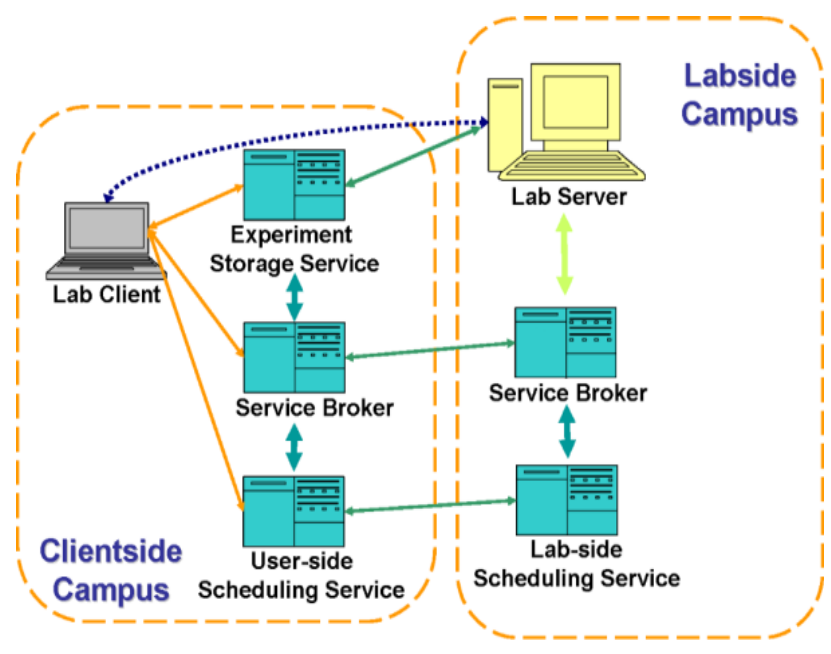

Figure 5. Interactiveilab Shared Architecture

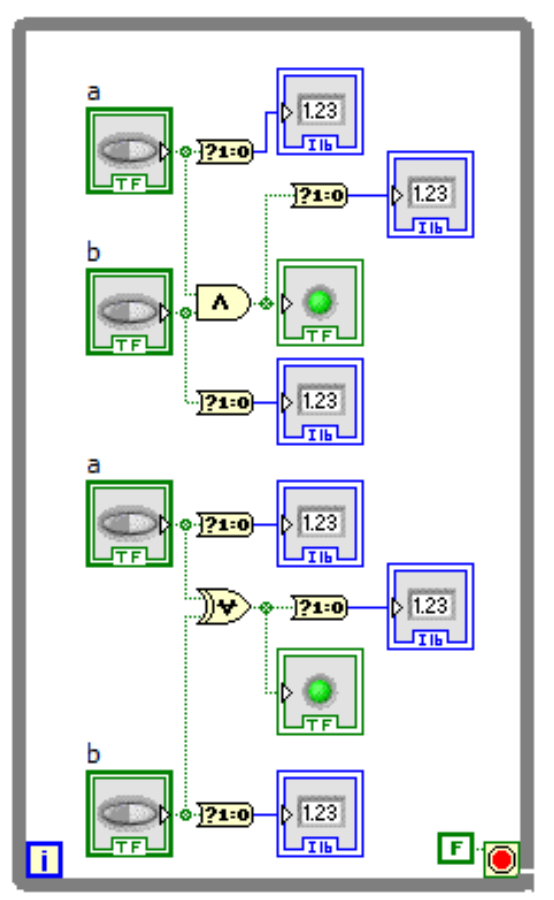

Figure 6. Block diagram of Gates

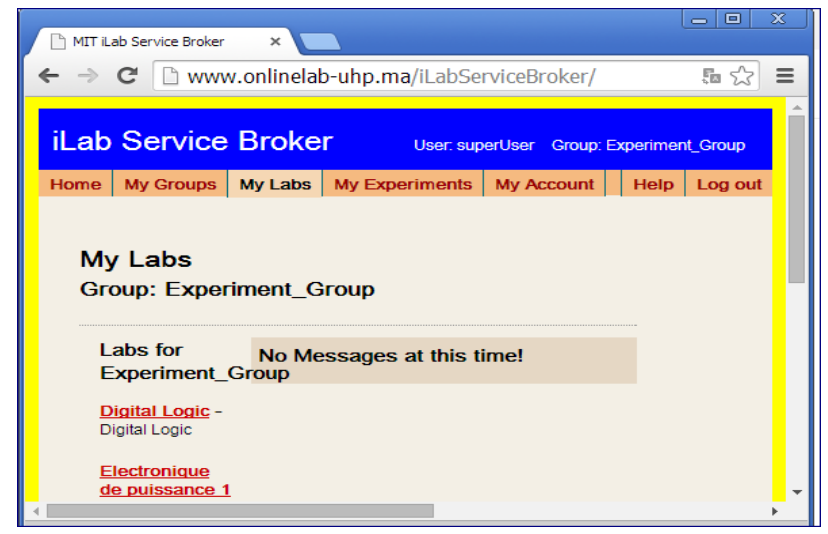

Figure 7. Available Experiments

The student manipulates and makes changes remotely by changing the values of $\mathrm{A}$ and $\mathrm{B}$ and obtains the result in the Truth table in real time (Fig.8). 


\section{Full Adder Remote Experiment}

An interesting application to understand the logic gates AND, OR and XOR and their interconnections is the implementation of a full Adder. Full Adder is the heart of an arithmetic logic unit that presents an essential part of any computer for all mathematic operations; Adder is to connect two half-Adders and an OR gate. In this experiment, the user can demonstrate the binary addition and learn to perform and use binary arithmetic circuits (Fig.9).

\section{Flip-Flops Remote Experiment}

JK flip-flop is a mostly clocked logic device implemented as the master slave, which is able to store one bit of information. The objective of this experiment is to enable students to determine the logic of JK flip-flops, to observe their state transition, and then to analyze the timing diagram (Fig.10).

\section{E. 4 bits Binary Counter Remote Experiment}

A counter is a sequential circuit that goes through a sequence of states upon the application of input pulses. It is considered as the most useful and versatile subsystem of a digital branch. The objective of this experiment is to help students demonstrate the operations and recognize the characteristics of a synchronous 4 bit binary counter. There are 7 display segments that show the corresponding decimal value for the 4 states of counter (Fig.11).

\section{CONCLUSION \& FUTURE WORKS}

This work focuses on the implementation of an online digital laboratory that provides several experiences in digital sequential circuits. It is based on the FPGA, the NI ELVIS platform, and the interactive ISA. The present implementation is contributing to the increase of remote labs in the network of online labs to help more than 1,000 students from different engineering curricula remotely perform and execute their experiments in digital electronics.

\section{REFERENCES}

[1] Ahmed Naddami, Ahmed Fahli, MouradGourmaj, Mohammed Moussetad, " Determination of the synchronous machine's parameters using the iLab Shared Architecture " ,IJOE, Vol 10, No 3 (2014).

[2] T. Zimmer, D. Geoffroy, A. Pester, R. Oros, T. Tsiatsos and S. Douka - eSience: Setting up a network of remote labs in the magrebian countries, ICEEL 2013, Marrakesh, Morocco, 1 -5 July 2013

[3] Tawfik, M. , Pesquera, A. ; Gil, R. ; Martin, S. ; Diaz, G. ; Peire, J. ; Castro, M. ; Pastor, R. ; Ros, S. ; Hernandez, R. "Shareable educational architectures for remote laboratories"TAEEconference,Vigo, 13-15 June 2012

[4] James Feher,"Introduction to Digital Logic with Laboratory Exercises" Copyright (C) 2009 James Feher

[5] http://www.ehow.com/about_4564073_digital-electro

[6] http://www.ni.com/

[7] http://www.esience.org/

[8] http://www.weblab.deusto.es/

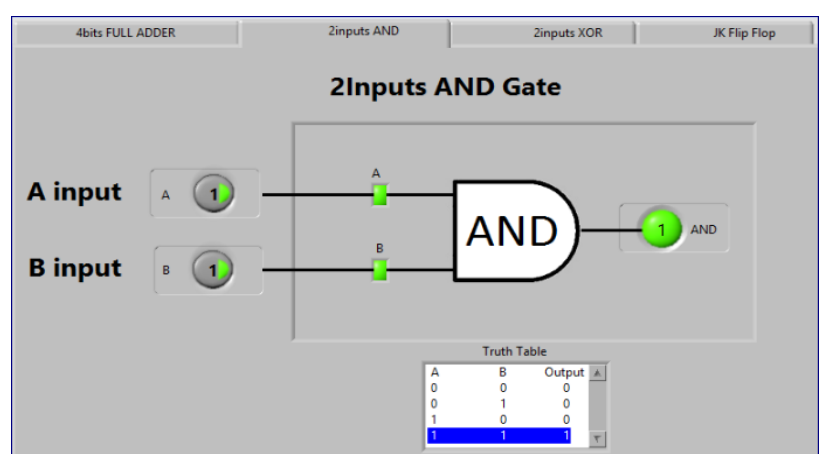

Figure 8. 2 Inputs AND User Interface

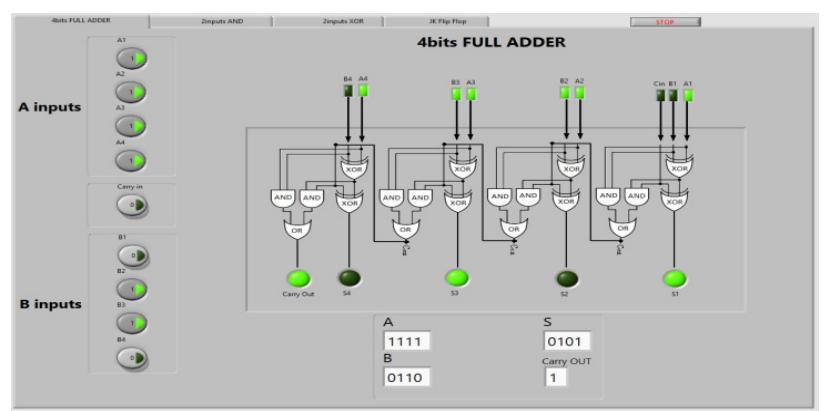

Figure 9. Full Adder User Interface

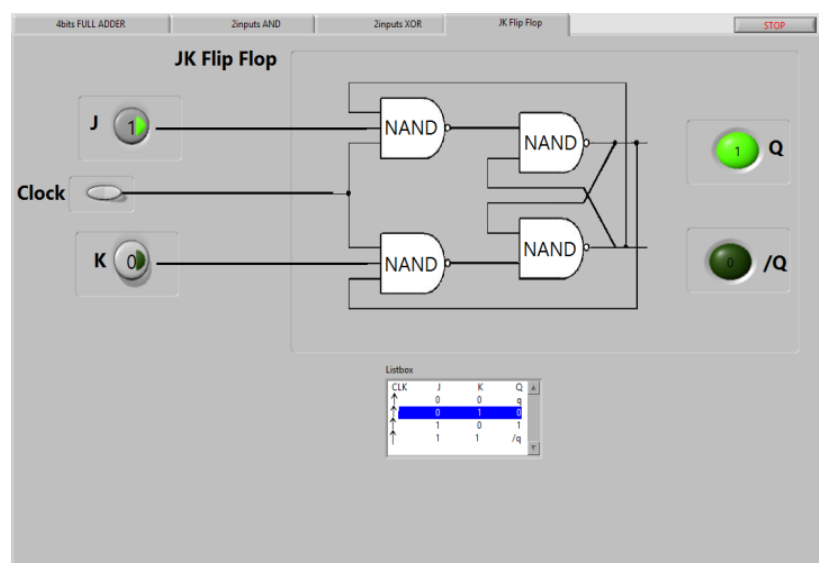

Figure 10. JK Flip-Flop User Interface

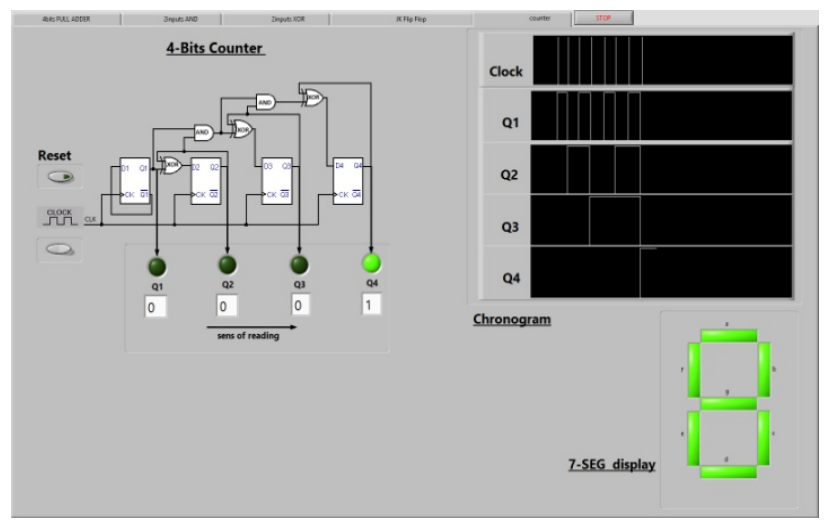

Figure 11. 4 bits Binary Counter User Interface 
[9] Orduña, P. (2013). Transitive and scalable federation model for remote laboratories. $\mathrm{PhD}$ Thesis, Universidad de Deusto. http://www.weblab.deusto.es/pub/dissertation pablo.pdf

[10] Ahmed Naddami, Ahmed Fahli, MouradGourmaj, Andreas Pester, Ramona Oros " Importance of a network of online labs in magrebian countries" Proceedings of the IEEE , REV14 Conference, pp.77-78, Porto 26-28 February, 2014

[11] http://www.ni.com/ni-elvis/applications/

[12] http://www.ni.com/white-paper/8596/en

[13] Harward, V.J., et al, "The iLab Shared Architecture: A Web Services Infrastructure to Build Communities of Internet Accessible Laboratories," Proceedings of the IEEE, vol.96, no.6, pp.931-950, June 2008 http://dx.doi.org/10.1109/JPROC.2008.921607

[14] Kimberly DeLong, V. JudsonHarward, Philip Bailey, James Hardison, Gordon Kohse, YakovOstrocsky"Three Online Neutron Beam Experiments Based on the iLabShared Architecture", Education Engineering (EDUCON), Madrid,pp .145 - 150,14-16 April 2010.

[15] Hardison, J., DeLong, K., Bailey, P., Harward, V.J., "Deploying Interactive Remote Labs Using the iLab Shared Architecture," Frontiers in Education (FIE) Conference, Saratoga Springs, New York, October 22-25, 2008

[16] Barry Paton Dalhousie ,"Fundamentals of Digital Electronics" Copyright (C) 1998 by National Instruments Corporation

\section{AUTHORS}

Ahmed Naddami is with the Laboratoire MATIC, Department of Electrical Engineering, The Polydisciplinary Faculty in Khouribga, Hassan $1^{\text {st }}$ University-Settat, Morocco (e-mail: ahmed.naddami@gmail.com).

Ahmed Fahli is with the Laboratoire MATIC, Faculty of Sciences Ben M'Sik in Casablanca, Hassan II University Mohammedia, Morocco (e-mail:fahli@uhp.ac.ma).

MouradGourmaj is with the Laboratoire MATIC, Department of Electrical Engineering, The Polydisciplinary Faculty in Khouribga, Hassan $1^{\text {st }}$ University-Settat, Morocco (e-mail: mourad.gourmaj@gmail.com).

Mohammed Moussetad is with the Laboratoire LIMAT, Faculty of Sciences Ben M'Sik in Casablanca, Hassan II University Mohammedia, Morocco (e-mail: m.moussetad@gmail.com).

This project has been funded with support from the European Commission. This publication reflects the views of only the author, and the Commission cannot be held responsible for any use which may be made of the information contained therein. Submitted 15 January 2015. Published as resubmitted by the authors 23 March 2015. 